\title{
Highly-closed/-Open Porous Ceramics with Micro-Beads by Direct Foaming
}

\author{
Woo Young Jang, Dong Nam Seo, Jung Gyu Park, Hyung Tae Kim*, Sung Min Lee*, \\ Suk Young Kim**, and Ik Jin Kim ${ }^{\dagger}$ \\ Institute of Processing and Application of Inorganic Materials (PAIM), \\ Department of Advanced Materials Science and Engineering, Hanseo University, Seosan 31962, Korea \\ *Engineering Ceramics Team, Korea Institute of Ceramic Engineering and Technology (KICET), Icheon 17303, Korea \\ ** School of Materials Science \& Engineering, Yeungnam University, Gyeongsan 38541, Korea \\ (Received August 5, 2016; Revised October 26, 2016; Accepted October 31, 2016)
}

\begin{abstract}
This study reports on wet-foam stability with respect to porous ceramics from a particle-stabilized colloidal suspension that is achieved through the addition of polymethyl methacrylate (PMMA) using a wet process. To stabilize the wet foam, an initial colloidal suspension of $\mathrm{Al}_{2} \mathrm{O}_{3}$ was partially hydrophobized by the surfactant propyl gallate (2 wt.\%) and $\mathrm{SiO}_{2}$ was added as a stabilizer. The influence of the PMMA content on the bubble size, pore size, and pore distribution in terms of the contact angle, surface tension, adsorption free energy, and Laplace pressure are described in this paper. The results show a wet-foam stability of more than $83 \%$, which corresponds to a particle free energy of $2.7 \times 10^{-12} \mathrm{~J}$ and a pressure difference of $61.1 \mathrm{mPa}$ for colloidal particles with 20 wt.\% of PMMA beads. It was possible to control the uniform distribution of the open/closed pores by increasing the PMMA content and by adding thick struts, leading to the achievement of a higher-stability wet foam for use in porous ceramics.
\end{abstract}

Key words : Porous ceramics, Direct foaming, PMMA beads, Colloidal suspension, Tailoring microstructure

\section{Introduction}

$\mathbf{I}^{\mathrm{n}}$ norganic wet foams are used as porous ceramics or intermediate products in numerous potential applications ranging from the catalysis, adsorption, and separation regarding the filtration of molten metals and hot gases to refractory materials and bio-ceramics. ${ }^{1-3)}$ The direct-foaming method involves the production of a porous material through the direct incorporation of air into a suspension or liquid media; here, the bubbles are incorporated in a wet state that must be set and, in most cases, must also be sintered to maintain the structure of the pores. The air-water interface in the wet foams is, however, thermodynamically unstable due to the high interfacial energy of the foams, and this interface must be stabilized for the maintenance of the porous structure. ${ }^{4,5)}$ The typical destabilization mechanisms of foam are drainage, coalescence, and Ostwald ripening. Ostwald ripening occurs due to differences of the Laplace pressure that exists inside bubbles of differing sizes, whereby a steady diffusion of gas from smaller bubbles to larger ones occurs over time. These effects can be partially overcome through stabilization of the air with respect to the water interface. ${ }^{6,7)}$

Wet foam with surfactants can be stabilized using par-

†Corresponding author: Ik Jin Kim

E-mail : ijkim@hanseo.ac.kr

Tel : +82-41-660-1441 Fax : +82-41-660-1402 tially hydrophobized particles, as follows: the in situ hydrophobization of initially hydrophilic particles enables the attachment of particles to the gas-liquid interface; shortchain amphiphilic molecules that contain fewer than eight carbons in the hydrocarbon tail are then adsorbed on the particles to impart surface hydrophobicity; and, finally, the surface-hydrophobized particles in the colloidal suspension and their adsorption to the air-water interface enables the stabilization of high-volume wet foams. For highly porous ceramics, these wet foams showed neither bubble growth nor drainage over more than two days. ${ }^{8,9}$

The advantages of closed-cell porous ceramics over opencell structures include certain properties such as mechanical strength and thermal resistance; however, there exist numerous applications in which open-cell, interconnected structures are needed. Bone grafts, replacements, and filter materials, for example, require porous ceramics with a $150 \mu \mathrm{m}$-to-300 $\mu \mathrm{m}$ open cellular matrix. ${ }^{10,11)}$ The focus of the techniques and principles that are described here is the use of bead materials as foaming agents to modify our novel foaming processing route; the consequent generation of closed/open microporous structures is achieved via the use of micro-beads. ${ }^{12-14)}$

It is proved here that the effectiveness of micro-beads and the resultant effects of these micro-beads in terms of the stabilization of wet foams depend on factors such as interparticle interactions, wettability, and Laplace-pressure differences. Particles with pore formers stabilize wet foams by 
providing a steric hindrance against the coalescence of bubbles; also, the colloidal and rheological properties of the interface are modified to tailor the microstructure of the porous ceramics. The microstructures of cellular ceramics, including the pore morphology, porosity, and pore-size distribution, are characterized in this paper.

\section{Experimental Procedure}

\subsection{Materials}

The metal-oxide particles that were used in the experiments are $\alpha-\mathrm{Al}_{2} \mathrm{O}_{3}$ powder (KC, South Korea) with a mean particle diameter $\left(\mathrm{d}_{50}\right)$ of $4 \mu \mathrm{m}$ and a density of $3.95 \mathrm{~g} / \mathrm{cm}^{3}$ and $\mathrm{SiO}_{2}$ powder (Junsei Chemicals Co. Ltd, Japan) with $\mathrm{d}_{50}=3.5 \mu \mathrm{m}$ and a density of $2.65 \mathrm{~g} / \mathrm{cm}^{3}$. The other chemicals are propyl gallate (98\% Fluka, Germany), which was used as a surfactant, hydrochloric acid (35\% Yakuri Pure Chemicals, Osaka, Japan), and sodium-hydroxide powder (Yakuri Pure Chemicals, Kyoto, Japan). The microcellular foams of the porous ceramics are produced here through the elimination of PMMA microbeads, which is achieved through thermal degradation. The PMMA (LG MMA Chemicals, Korea) comprises a particles of moderate distribution and sizes smaller than $125 \mu \mathrm{m}$, while the average particle size is $211.9 \mu \mathrm{m}$, as shown in Fig. 1 .

\subsection{Preparation of suspension}

The a- $\mathrm{Al}_{2} \mathrm{O}_{3}$ powder $\left(\mathrm{d}_{50} \sim 4 \mathrm{~mm}\right.$; KC, South Korea) and $\mathrm{SiO}_{2}$ powder $\left(\mathrm{d}_{50} \sim 3.5 \mathrm{~mm}\right.$, Junsei Chemicals Co. Ltd, Japan) were added to de-ionized water, while an aqueous colloidal suspension was prepared separately. With the use of polyethylene bottles and zirconia balls (10 $\mathrm{mm}$ diameter) and the application of a ball/powder ratio of $2: 1$, homogenization and de-agglomeration of the suspension was carried out in a ball mill for at least $48 \mathrm{~h}$ at a rotation speed of $60 \mathrm{rpm}$. After the ball milling, $0.2 \mathrm{wt} \%$ of propyl gallate (Fluka Analytical, Germany) was added to the $\mathrm{Al}_{2} \mathrm{O}_{3}$ suspension as a surface modifier to hydrophobize the surfaces of the $\mathrm{Al}_{2} \mathrm{O}_{3}$ particles. The $\mathrm{pH}$ of the suspension was adjusted to 4.75 by drop-wise adding of (4) $\mathrm{M} \mathrm{NaOH}$ and/or (10) $\mathrm{N} \mathrm{HCl}$ (Yakuri Pure Chemicals, Japan). Through the addition of the required amount of water, the solid content of the final aqueous suspension was set at $30 \mathrm{Vol} \%$. The $\mathrm{SiO}_{2}$ suspension, which was also homogenized and ball-milled, was then added to the $\mathrm{Al}_{2} \mathrm{O}_{3}$ suspension to stabilize the wet foam at a molar concentration ratio of $1: 0.25 \mathrm{Al}_{2} \mathrm{O}_{3} / \mathrm{SiO}_{2}$. The PMMA beads were added to the final suspension at different wt- $\%$ to control the variation of the bubble and pore sizes. In the $30 \mathrm{~min}$ observation, the final suspension instantly foamed via mechanical frothing, as shown in Fig. 2.

\subsection{Colloidal suspension \& Foam characterization}

The surface tension and the contact angle of the final suspension were analyzed using the pendant-drop method (KSV Instruments Ltd, Helsinki, Finland). For the amphiphile-containing suspension, the drop volume was fixed at a constant value within the range of $5 \mathrm{ml}$ to $10 \mathrm{ml}$.

The energy of the attachment, or the free energy that was gained $(\mathrm{G})$ from the adsorption of a particle of radius $(r)$ at the interface, can therefore be calculated using the following equation:

$$
\mathrm{DG}=\pi \mathrm{r}^{2} \gamma_{\mathrm{aB}}(1-\cos \theta)^{2}
$$

where $\theta<90^{\circ}, \gamma$ is the surface tension of the suspension, and $\theta$ is the contact angle. The foaming of the final suspension was carried out at room temperature, and was achieved by using a household hand mixer (150 W, Super Mix, France) at its highest power for $15 \mathrm{~min}$. The mechanical frothing facilitated air incorporation throughout the whole volume of the suspension.

The air content was measured through a calculation of the percentage of the volume increase of the suspension postfoaming, as follows:

$$
\text { Air content }=\frac{\left(V_{\text {wet foam }}-V_{\text {suspension }}\right) \times 100}{V_{\text {wet foam }}}
$$

where $\mathrm{V}_{\text {wet foam }}$ indicates the post-foaming wet-foam volume and $\mathrm{V}_{\text {suspension }}$ indicates the post-foaming suspension volume.

The results of the Laplace pressure $(\Delta P)$ measurement imply that the difference between the inside and outside
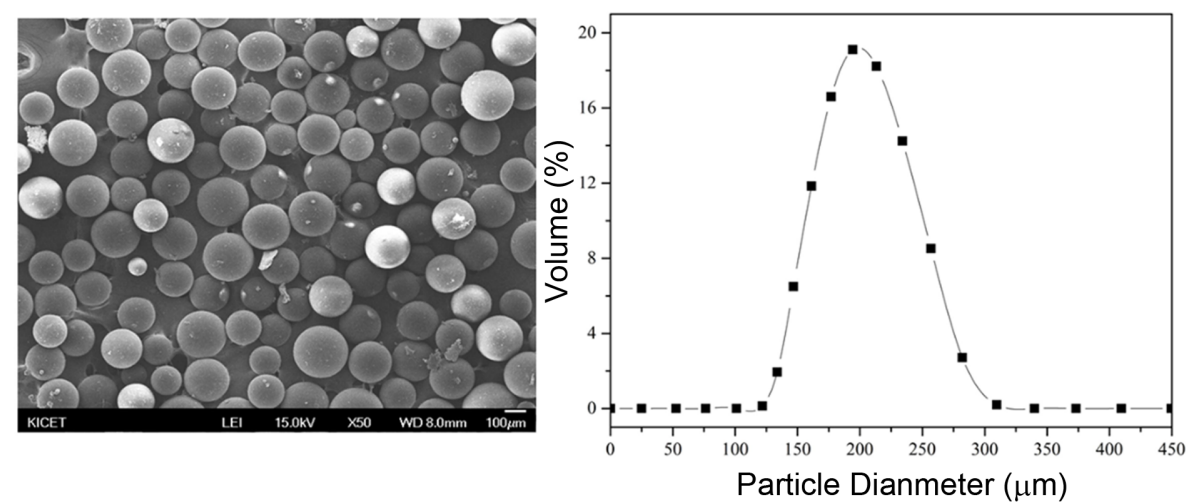

Fig. 1. SEM image and particle-size distribution of PMMA microbeads. 


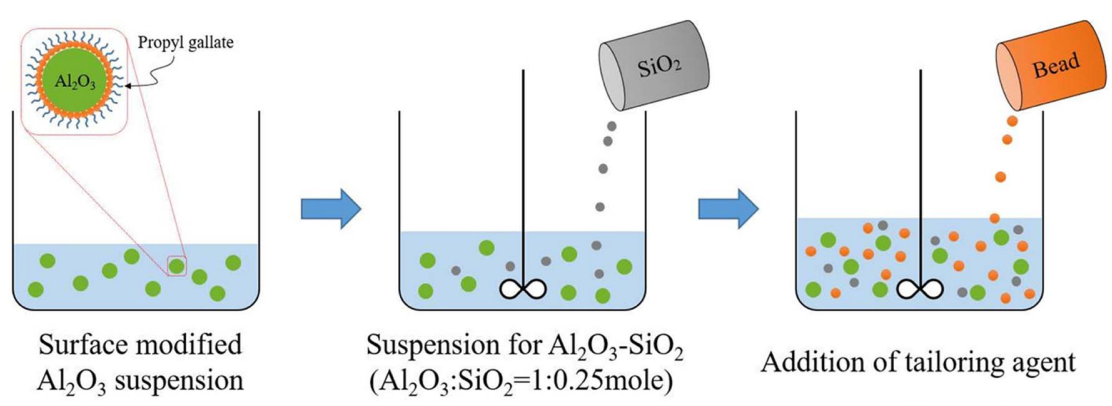

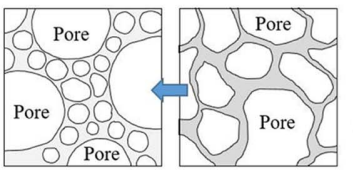

Porous ceramics

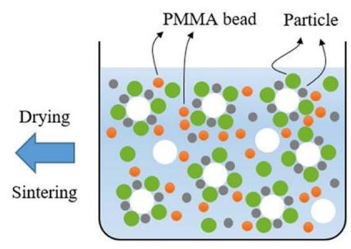

Wet foam

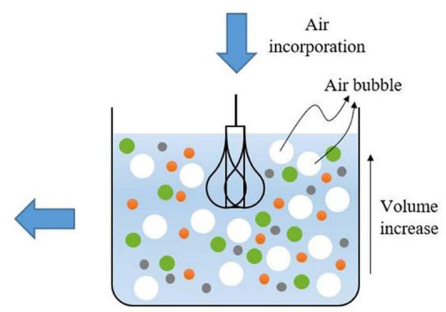

Direct foaming

Fig. 2. Schematic diagram of direct-foaming technique during preparation of porous $\mathrm{Al}_{2} \mathrm{O}_{3} / \mathrm{SiO}_{2}$ ceramics.

pressures of a gas bubble is an important parameter to consider for the stabilization mechanism, as follows:

$$
\Delta \mathrm{P}=\gamma\left(\frac{1}{R_{1}}+\frac{1}{R_{2}}\right)=\frac{2 \gamma}{R}(\text { Spherical bubble })
$$

where $\gamma$ is the surface tension of the suspension and $R_{1}$ and $R_{2}$ are the radii of the two interfacing bubbles. For spherical-shaped bubbles, however, $R_{1}$ and $R_{2}$ are equal; therefore, the Laplace pressure is denoted by $2 \gamma / \mathrm{R}$.

To investigate the wet-foam stability, the wet-foam samples were put into cylindrical molds of constant volume and left for $48 \mathrm{~h}$. The foam stability was then evaluated upon observation of the percentage of the volume loss of the foam, as follows:

$$
\text { Wet foam stability }=\frac{V_{\text {Final }}}{V_{\text {Initaial }}} \times 100
$$

where $\mathrm{V}_{\text {Final }}$ indicates the wet-foam volume after $48 \mathrm{~h}$ and $\mathrm{V}_{\text {Initial }}$ indicates the wet-foam volume before $48 \mathrm{~h}$.

The average wet-bubble size was measured through an analysis of the optical-microscope images, for which linearintercept software was used (TU Darmstadt, Germany). The optical microscope (Somtech Vision, South Korea) was in transmission mode and was connected to a digital camera.

\subsection{Direct foaming, drying, sintering, and analysis}

The wet foams were put into cylindrical molds and left to dry at room temperature $\left(22^{\circ} \mathrm{C}\right.$ to $\left.25^{\circ} \mathrm{C}\right)$ for $24 \mathrm{~h}$ to $48 \mathrm{~h}$. After drying, the specimens were sintered in a super kantal furnace $\left(\max 1650^{\circ} \mathrm{C}\right)$ at $1300^{\circ} \mathrm{C}$ for $1 \mathrm{~h}$. The heating and cooling rates were set at $1^{\circ} \mathrm{C} / \mathrm{min}$ and $3^{\circ} \mathrm{C} / \mathrm{min}$, respectively. The microstructures of the sintered foams were observed using a field-emission scanning electron microscope (FESEM) (JEOL, Japan). The resulting porosity was calculated from the true and apparent density values using the following equation:

$$
\text { Porosity }(\%)=\left(\frac{\text { True density }- \text { Apparent density }}{\text { True density }}\right) \times 100(5)
$$

\section{Results and Discussion}

Figure 3 shows the changes of the contact angle and the surface tension of the $\mathrm{Al}_{2} \mathrm{O}_{3} / \mathrm{SiO}_{2}(1: 0.25)$ molar suspension in terms of the addition of different bead contents. To produce remarkably stable foams that exhibit lifetimes of several days or weeks, the colloidal particles must be adsorbed on the surfaces of the air bubbles. Attachment of the parti-

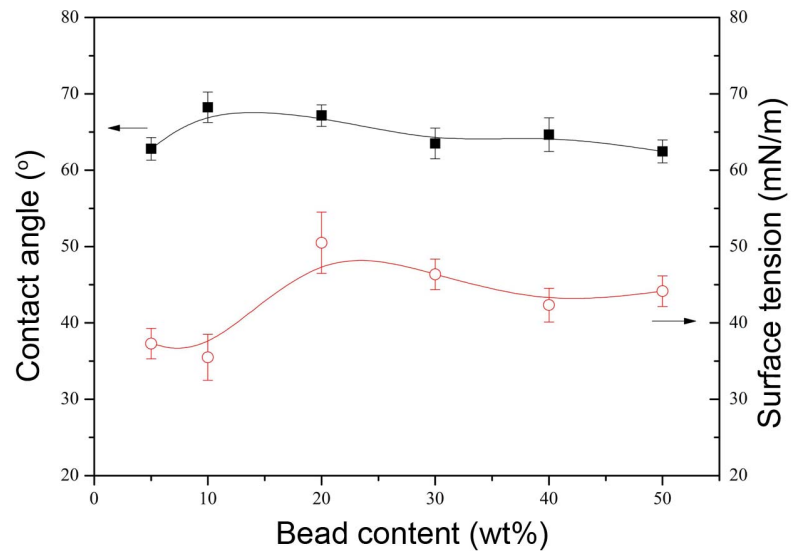

Fig. 3. Contact angle and surface tension of colloidal suspension with respect to bead content of colloidal suspension. 
cles at the gas-liquid interfaces occurs when the particles are not completely wetted; that is, the particles are partially hydrophobic. These partially hydrophobic particles are positioned primarily in the liquid phase, and a contact angle of $<90^{\circ}$ is displayed; therefore, a simple way to describe the particle position at the interface is through a measurement of the contact angle. ${ }^{6,12)}$ The mean contact angle of the $\mathrm{Al}_{2} \mathrm{O}_{3}$ suspension decreased slightly with increasing of the PMMA-bead content; as can be seen in Fig. 3, the contact angle is $67^{\circ}$, while the surface tension is at its maximum of $\sim 50 \mathrm{mN} \mathrm{m}^{-1}$ at a $20 \mathrm{wt}-\%$ bead content. These findings show that with increasing of the bead content, the particles become much more concentrated in the colloidal suspension, and the contact angle decreases very gradually as a result. This decrease is in part due to the presence of bead materials in the suspension, which materials are adsorbed at the air-water interface. ${ }^{15)}$

Figure 4 establishes the relationship between the adsorption free energies, which correspond to the wet foam stability as a function of the different levels of bead-content wt\% that were added to the initial suspension. The particles that are attached to the gas-liquid interfaces of the foams lower the systemic free energy by replacing a part of the gas-liquid interfacial area; therefore, the measurement of the adsorption free energy is an important aspect of the processing of particle-stabilized wet foams. ${ }^{15,16)}$ The investigated samples exhibit high values of adsorption free energy from approximately $2.0 \times 10^{-12} \mathrm{~J}$ to $3.8 \times 10^{-12} \mathrm{~J}$ at the interface. This moderately high energy, which is associated with irreversible adsorption of the particles at the air-water interface, leads to the outstanding stability (within the range of $70 \%$ to $83 \%$ ) that is exhibited by the particle-stabilized wet foams. In the case of the surfactant-stabilized wet foam, the adsorption free energy values of the surfactant molecules range within a few joules, thereby limiting the foam stability, ${ }^{2,8,15,18)}$ moreover, the wet-foam stability of the ceramic foam is $>83 \%$, and this proves that the addition of PMMA beads at levels up to $20 \mathrm{wt} \%$ moderately increases the stability of the wet foams.

Figure 5 shows the air content of the suspension and the

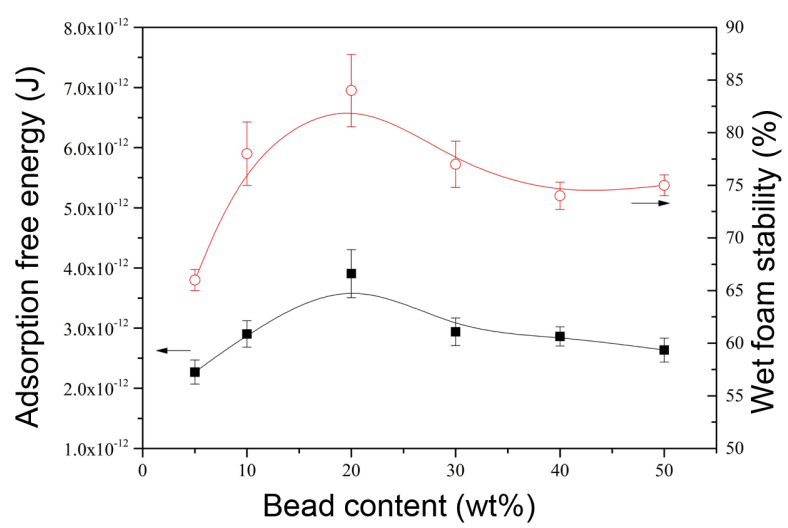

Fig. 4. Adsorption free energy and wet-foam stability with respect to bead content of colloidal suspension. porosity of the sintered sample as a function of the bead content. The influence of the bead content on the air content and porosity can be observed, suggesting that the porosity increases with an increases in the air content that are up to $40 \%$ of the bead content; here, a part of the reason for these effects that the collapsing tendency of the bubbles drops with the post-foaming increase of air in the suspension and, as a result, the wet-foam stability increases, which leads to the increase in porosity. When the air that is incorporated into the suspension decreases, the stability of the wet foams increases and this, upon sintering, increases the porosity correspondingly. The maximum air content of 72.5 was observed in the initial suspension without PMMA beads; this air content value corresponds to a porosity of $50 \%$. Upon adding bead at a level up to $40 \%$, the increment of air content rises to $77.5 \%$, and correspondingly porosity of $>65 \%$ was achieved. The total porosity of the sintered ceramics is proportional to the quantity of bubbles that is incorporated in the suspension during the foaming process.

In general, the bubble size of the suspension, as well as the pore size of the thin film or the struts that are formed after the foaming of the particles, stabilizes the suspension; sintering is described in terms of attractive and repulsive interactions between bubbles. Single layers or multilayers of the modified particles that were observed on the thin films can withstand changes of the pressure between the bubbles, thereby maintaining the stability of the films. Electrostatic forces, steric repulsions, or ligand-exchange reactions can overcome the Van der Waals force, ${ }^{16,17)}$ while the process can be slowed down with the use of surfactants, which are adsorbed at the interface; this can also decrease the interfacial energy. The degree of hydrophobicity that is achieved by using the surfactant, as well as the bead content, is related to the wet-foam stability, which leads to an apparent decrease of the surface tension of the suspension through the replacement of a part of the highly energetic interface area and the reduction of the free energy of the system. ${ }^{18)}$

Figure 6 shows that the average bubble size decreased from $150 \mu \mathrm{m}$ to $115 \mu \mathrm{m}$ with an increase of the bead content

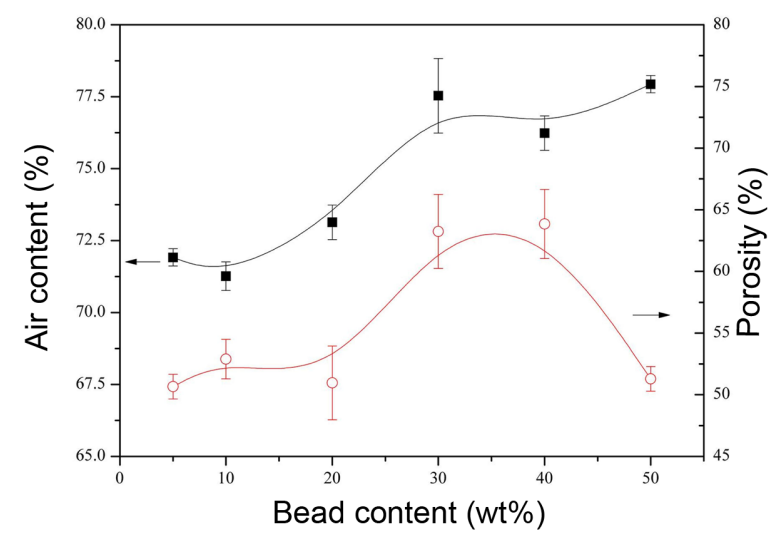

Fig. 5. Air content and porosity of suspension with respect to bead content of colloidal suspension. 


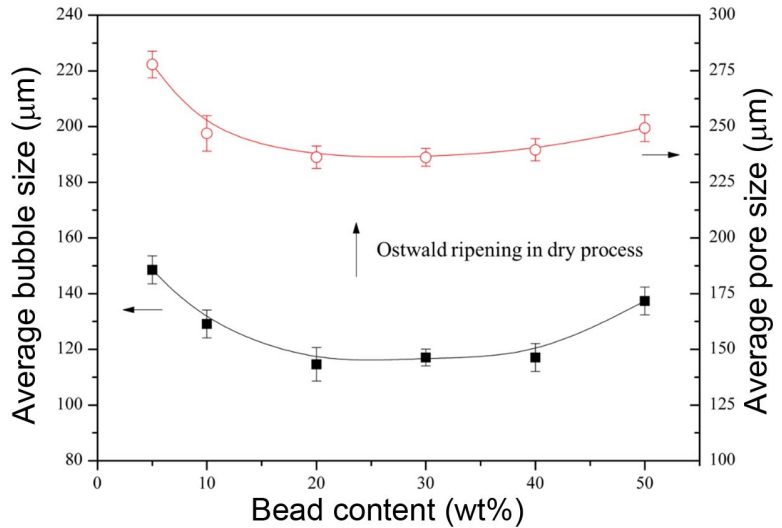

Fig. 6. Average bubble size and pore size with respect to bead content of particle-stabilized foams that contain PMMA beads as template.

to $20 \mathrm{wt} \%$; this bead content increase due to the decrease of the surface tension and the increase of the foam viscosity, both of which result from higher particle concentrations. ${ }^{16)}$ Air-bubble resistance against rupturing is consequently reduced and, in turn, foams with average bubble sizes are produced; however, the absolute increase of the average pore size after the sintering process is greater than that of the average bubble size in the wet foam because of Ostwald ripening during the drying process. Differences of Laplace pressure between bubbles of distinct sizes lead to bubble disproportionation and Ostwald ripening; these processes are the result of the gradual transition of the steady diffusion of the gas molecules from smaller to larger bubbles. ${ }^{16-18)}$

In the present experiment, the bubbles are almost spherical, and the above equation is used because of the narrow bubble size distribution. From the equation, it can be seen that bubbles of smaller radius are under higher pressure than those of larger radii, and this results in the transition of the gas diffusion from smaller to larger bubbles, which then leads to destabilization of the foam, as shown in Fig. 6 . Amphiphiles are therefore used because they reduce the surface tension of the gas-liquid interface, which decreases the Laplace pressure and prolongs the lifespans of the newly formed bubbles. ${ }^{18)}$ Fig. 7 reveals the gradual increase of the Laplace pressure from $0.57 \mathrm{mPa}$ to $0.85 \mathrm{mPa}$ that occurs for up to $30 \mathrm{wt} \%$ of bead content; this gradual increase can be attributed to the gradual decrease of the bubble size from $150 \mu \mathrm{m}$ to $115 \mu \mathrm{m}$; here, bubble coarsening, as well as Ostwald ripening, is limited by the production of thermodynamically stable wet foam. ${ }^{16-18)}$ In the present study, the wet-foam stability of the ceramic foams increased with increasing of the bead content of the colloidal suspension to a maximum of $>83 \%$. The average bubble size corresponds to the ratio between the actual and the initial average bubble sizes, which were calculated as a function of the time after the foaming.

In terms of the bead content, Fig. 8 shows well-developed

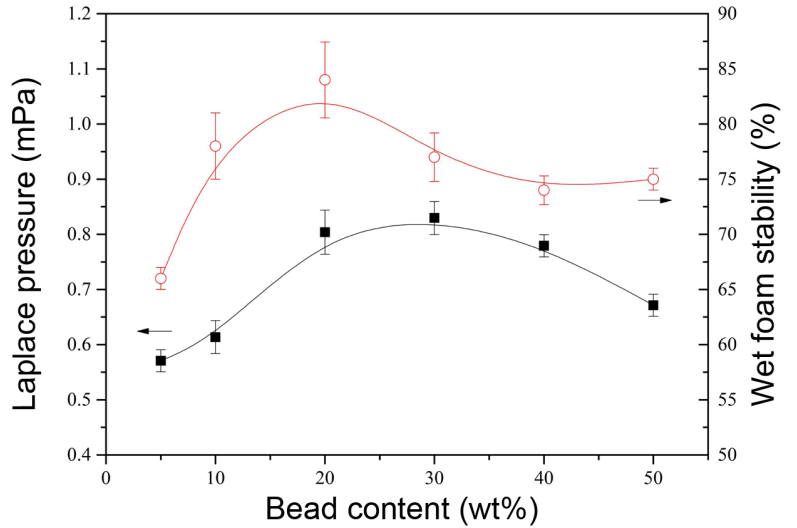

Fig. 7. Laplace pressure and wet-foam stability with respect to bead content of colloidal suspension.

microstructures with the narrow pore-size distributions of porous ceramics. Two distinctive pore ranges of approximately $300 \mu \mathrm{m}$ to $500 \mu \mathrm{m}$ (large) and $150 \mu \mathrm{m}$ to $200 \mu \mathrm{m}$ (small) were identified, suggesting that the pore-size distribution is bimodal in all of the samples. The large pores were large spherical pores that induced air bubbles through direct foaming, whereas the small ones represent windows in the spherical pore wall that result from the pyrolysis of the bead materials that occurs during sintering. These small pores provide a hierarchical open/closed pore distribution from the larger to the smaller pores and to the thick struts (films in wet foams); this organization leads to more stable foams that can be sintered to form porous ceramics with high mechanical strength; furthermore, the large pore sizes, which are beyond the range of $300 \mu \mathrm{m}$ to $700 \mu \mathrm{m}$, can be attributed to Ostwald ripening; these values are determined according to the low wet-foam stabilities of approximately $66 \%$ and $75 \%$, as shown in Figs. 8(a) and 8(f), respectively.

\section{Conclusions}

With the addition of bead content via direct foaming, the microstructure of a wet foam can be well-tailored to open/ closed porous ceramics, which are formed as particle-stabilized colloidal suspensions. The initial colloidal suspension of $\mathrm{Al}_{2} \mathrm{O}_{3}$ was partially hydrophobized by the surfactant propyl gallate (2 wt.\%); the wet foam was well-stabilized by using $\mathrm{SiO}_{2}$ as a stabilizer. The results show a wet-foam stability of more than $83 \%$, which corresponds to a particle free energy of $7.0 \times 10^{-12} \mathrm{~J}$, and a pressure difference of $1.1 \mathrm{mPa}$ for colloidal particles with $20 \mathrm{wt} . \%$ of PMMA. It was possible to control the uniform distribution of open/closed pores by increasing the bead content and the number of thick struts; these changes lead to higher stability of the wet foam which is useful for the formation of porous ceramics. 

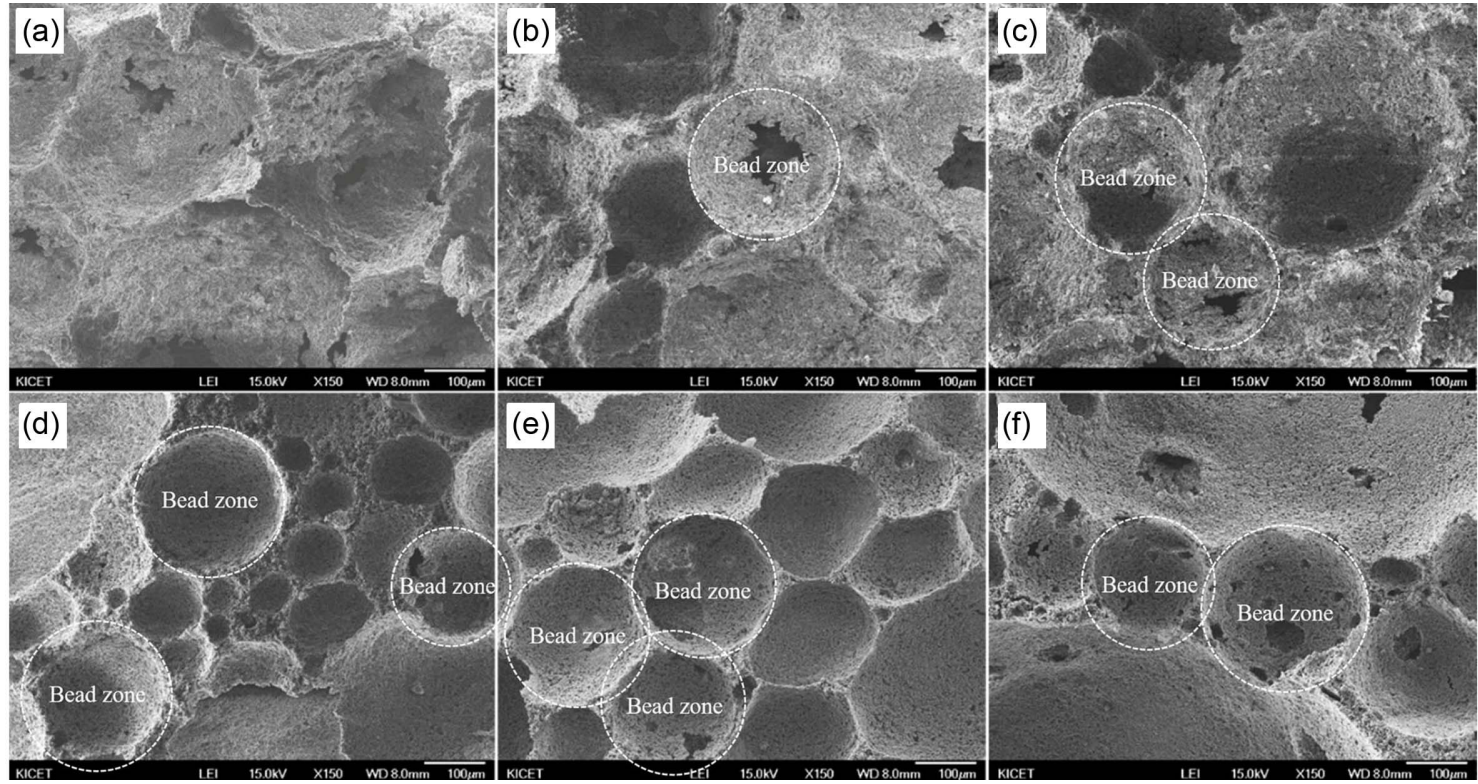

Fig. 8. Microstructures of sintered porous ceramics with respect to bead content, (a) 0, (b) 5, (c) 10, (d) 20 , (e) 30 , and (f) 50 wt\%.

\section{Acknowledgments}

This research was financially supported by Hanseo University, Korea.

\section{REFERENCES}

1. M. Scheffler and P. Colombo, Cellular Ceramics: Structure, Manufacturing, Properties and Applications; pp. 645, John Wiley \& Sons, Weinheim, 2005.

2. J. C. H. Wong, E. Tervoort, S. Busato, U .T. Gonzenbach, A. R. Studart, P. Ermanni, and L. J. Gauckler, "Designing Macroporous Polymers from Particle-stabilized Foams," J. Mater. Chem., 20 [27] 5628-40 (2010).

3. N. Sarkar, J. G. Park, S. Mazumder, and I. J. Kim, " $\mathrm{Al}_{2} \mathrm{TiO}_{5}$-Mullite Porous Ceramics from Particle Stabilized Wet Foam," Ceram. Int., 41 [5] 6306-11 (2015).

4. C. Vakifahmetoglu, M. Balliana, and P. Colombo, "Ceramic Foams and Micro-beads from Emulsions of a Preceramic Polymer," J. Eur. Ceram. Soc., 31 [8] 1481-90 (2011).

5. S. Bhaskar, J. G. Park, S. W. Kim, H. T. Kim, and I. J. Kim, "Micro Porous Ceramics using Partially Hydrophobized $\mathrm{SiO}_{2}-\mathrm{SiC}$ Particle by Direct Foaming," J. Ceram. Soc. Jpn, 123 378-82 (2015).

6. A. Pokhrel, S. D. Nam, S. T. Lee, and I. J. Kim: "Processing of Porous Ceramics by Direct Foaming: A Review," $J$. Korean Ceram. Soc., 50 [2] 93-102 (2013).

7. B. S. Murray, "Stabilization of Bubbles and Foams," Curr. Opin. Colloid Interface Sci., 12 [4] 231-41 (2007).

8. T. S. Horozov, "Foams and Foam Films Stabilized by Solid Particles," Curr. Opin. Colloid Interface Sci., 13 [3] 134-40 (2008).

9. K. D. Danov and P. A. Kralchevsky, "The Standard Free Energy of Surfactant Adsorption at Air/Water and Oil/ Water Interfaces: Theoretical vs. Empirical Approaches,"
Colloid J., 74 [2] 172-85 (2012).

10. P. J. Wilde, "Interface: their Role in Foam and Emulsion Behavior," Curr. Opin. Colloid Interface. Sci., 5 [3] 176-81 (2000).

11. N. Sarkar, J. G. Park, S. Mazumder, D. N. Seo, and I. J. Kim, "Effect of Amphiphile Chain Length on Wet Foam Stability of Porous Ceramics," Ceram. Int., 41 [3] 4021-27 (2015).

12. M. Shibuya, T. Takahashi, and K. Koyama, "Microcellular Ceramics by Using Silicone Preceramic Polymer and PMMA Polymer Sacrificial Microbeads," Compos. Sci. Technol., 67 [1] 119-24 (2007).

13. P. Colombo and E. Bernardo, "Macro- and Micro-cellular, Porous Ceramics from Preceramic Polymers," Compos. Sci. Technol., 63 [16] 2353-59 (2003).

14. B. D. Stewart, L. G. Andrews, B. S. Pelletier, C. A. Daly Jr, and J. E. Boyd, "Porous PMMA-titania Composites: A Step towards more Sustainable Photocatalysis," J. Water Proc. Eng., 8 179-85 (2015).

15. U. T. Gonzenabach, A. R. Studart, E. Tervoort, and L. J. Gauckler, "Stabilization of Foams with Inorganic Colloidal Particles," Langmuir, 22 [26] 10983-88 (2006).

16. P. Sepulveda and J. G. P. Binner, "Processing of Cellular Ceramics by Foaming and in-situ Polymerization of Organic Monomers,” J. Eur. Ceram. Soc., 19 [12] 2059-66 (1999).

17. D. M.-Alguacil, E. Tervoort, C. Cattin, and L. J. Gauckler, "Contact Angle and Adsorbtion Behavior of Carboxylic Acids on $\alpha-\mathrm{Al}_{2} \mathrm{O}_{3}$ Surfaces," J. Colloid Interface Sci., 353 [2] 512-18 (2011).

18. N. Sarkar, J. G. Park, S. Mazumder, I. S. Han, T. H. Lim, and I. J. Kim, "Processing of Particle Stabilized $\mathrm{Al}_{2} \mathrm{TiO}_{5}$ $\mathrm{ZrTiO}_{4}$ foam to Porous Ceramics," J. Eur. Ceram. Soc., 35 [14] 3969-76 (2015). 